\title{
Investigation of the effect of the angle between drive shafts on vibration responses of main reducer
}

\author{
Xiaogang Liu ${ }^{1, *}$, Zhaoyu $\mathrm{Wu}^{1}$, Weiguang $\mathrm{Shu}^{2}$, and Jie $\mathrm{Lu}^{1}$ \\ ${ }^{1}$ School of Mechanical and Electronic Engineering, Wuhan University of Technology, Hubei 430070, \\ China \\ ${ }^{2}$ South-central University for Nationalities, Hubei 430074, China
}

\begin{abstract}
The drive shaft arrangement has a considerable influence on the vibration responses of the shaft-final drive system. In this research, a coupled vibration model is developed based on force analysis of hypoid gear and lumped mass method. The effect of time-varying mesh stiffness, gear backlash and transfer error are included to investigate the effect of the angle between drive shafts on vibration responses of main reducer. The vibration responses of main reducer are acquired using this model. The results show that the vibration amplitude of the gears of main reducer increase with the angle between drive shafts. This paper presents an analytical method to determine the value of the angle between drive shafts, so as to control the vibration of main reducer.
\end{abstract}

\section{Introduction}

As the requirement for comfort of automobile from customers is increasing, the requirement for vehicle vibration and noise control is becoming more demanding. The main reducer is a prominent source of vibration for automobile products and it has been investigated intensively. In the early stage, Singh [1] developed a mathematical model of single degree of freedom gear vibration with the backlash considered. Kahraman et al. [2, 3] developed a nonlinear vibration model of a spur gear system with rolling bearings, which took into account the bearing clearance and backlash. In addition, time-varying stiffness was introduced into the model, in which the single degree of freedom model was extended to a 3 degree of freedom coupled torsional vibration model with nonlinear backlash. A few years later, Kahraman and Blankenship [4] analysed vibration characteristics of nonlinear systems using periodic time-varying parameters and gear backlash under external excitation. Teodossiades et al. [5, 6] developed a model with time-varying meshing stiffness and nonlinear backlash to analyse the vibration characteristics of the gear.

To sum up, most of the studies are based on the dynamic performance analysis of the gear system. For automobile transmission system, the vibration analysis should not only consider the dynamic performance of gear system, but also the influence of the vibration generated by the drive shaft's excitation on main reducer. However, the effects of the drive

\footnotetext{
*Corresponding author: Xiaogang_liu@yahoo.com
} 
shaft arrangement and responses of the gear transmission system have not been investigated simultaneously in details.

In this research, a model about the coupled vibration of shaft-final drive system is developed, based on the models developed previously [7-10], which includes the inhomogeneity of multiple universal joint transfer and the nonlinear time-varying factors of gear system. Using this model, the vibration responses of gears at different values of angle between drive shafts are simulated.

\section{Methodologies}

In this part, the dynamic model of the shaft-final drive system is introduced, which is based on force analysis of gear system and lumped mass method, including coupled vibration model of gear pair and torsional vibration model of drive shaft.

\subsection{Hypoid gear model}

In this model, the uniformly distributed load along the contact line is simplified to a concentrated force acting on the midpoint of the tooth width. The force analysis of pinion as illustrated in Fig. 1.
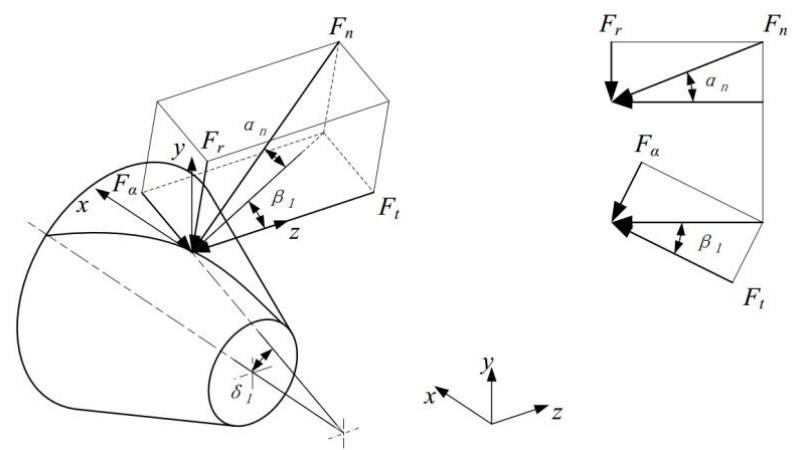

Fig. 1. Force analysis of pinion.

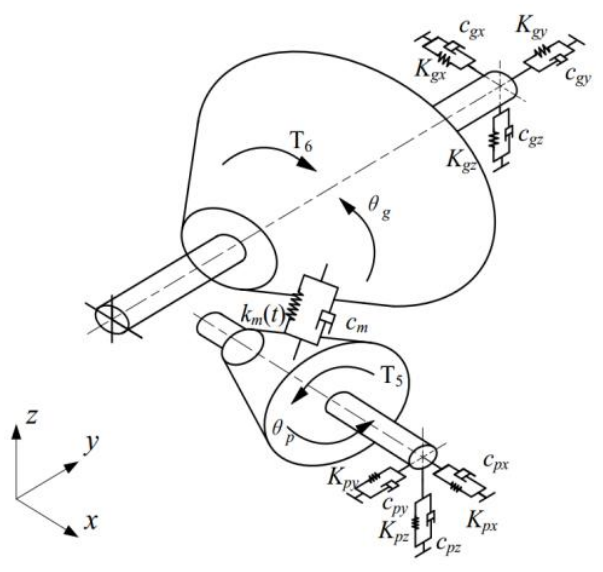

Fig. 2. The coupled vibration model of hypoid gears. 
According to [10], the normal dynamic meshing force of pinion and its components can be expressed as,

$$
\begin{gathered}
F_{n}=k_{m}(t) f\left(x_{n}\right)+c_{m} \dot{x}_{n} \\
\left\{\begin{array}{l}
F_{x}=-F_{n} \cos \alpha_{n} \sin \beta_{1} \cos \delta_{1}+F_{n} \sin \alpha_{n} \sin \delta_{1} \\
F_{y}=-F_{n} \cos \alpha_{n} \sin \beta_{1} \cos \delta_{1}-F_{n} \sin \alpha_{n} \cos \delta_{1} \\
F_{z}=-F_{n} \cos \alpha_{n} \cos \beta_{1}
\end{array}\right.
\end{gathered}
$$

where $c_{m}$ is the average damping of hypoid gear. $\dot{x}_{n}$ is the relative velocity between two gears at meshing point in the normal direction of meshing point. $k_{m}(t)$ is gear pair meshing stiffness function. $\delta_{1}$ is the pitch cone angle of the pinion. $\beta_{1}$ is mean spiral angle. $\alpha_{n}$ is average pressure angle. Their values are listed in Table 1.

Table 1. Parameters of pinion and gear.

\begin{tabular}{|l|c|c|}
\hline & Pinion & Gear \\
\hline The number of teeth & 8 & 41 \\
\hline Pitch cone angle & $12.75^{\circ}$ & $76.50^{\circ}$ \\
\hline Average pressure angle & $21.25^{\circ}$ & $21.25^{\circ}$ \\
\hline Mean spiral angle & $47.97^{\circ}$ & $28.27^{\circ}$ \\
\hline Radius of nodal circle & $18.8 \mathrm{~mm}$ & $71.7 \mathrm{~mm}$ \\
\hline
\end{tabular}

Using the lumped mass method as illustrated in Fig. 2, a coupled vibration model of a hypoid gear pair is developed. $c_{i j}$ is the equivalent damping in $x, y$ and $z$ direction (where $i$ $=p, g ; j=x, y, z) . K_{i j}$ is the equivalent stiffness in $x, y$ and $z$ direction (where $i=p, g ; j=x$, $y, z$ ). Their values are listed in Table 2 .

Table 2. The equivalent stiffness and damping of pinion and gear.

\begin{tabular}{|c|c|c|c|c|c|c|c|}
\hline \multicolumn{4}{|c|}{ Stiffness (N/m) } & \multicolumn{4}{c|}{ Damping (N·s/m) } \\
\hline$K_{p x}$ & 864250000 & $K_{g x}$ & 2820700000 & $c_{p x}$ & 1050 & $c_{g x}$ & 1000 \\
\hline$K_{p y}$ & 1635600000 & $K_{g y}$ & 692000000 & $c_{p y}$ & 1050 & $c_{g y}$ & 1000 \\
\hline$K_{p z}$ & 1635600000 & $K_{g z}$ & 2820700000 & $c_{p z}$ & 1050 & $c_{g z}$ & 1000 \\
\hline
\end{tabular}

\subsection{Nonlinear dynamic model of shaft-final drive system}

In this paper, the lumped mass method is used to develop the mechanical model of the shaft-final drive system. Using this method, universal joint, gears, differential and hub are simplified as lumped rotary inertia. Rotary inertia of the drive shaft is assigned to universal joint that is connected to it. Gears and differential are simplified as lumped mass; drive shaft is replaced by a torsion spring and a damper; bearing is taken as a massless elastomer, replaced by a spring and a damper.

The torsional vibration model of the shaft-final drive system is illustrated in Fig. 3, where $K_{i}$ is the equivalent stiffness of drive shafts and half shafts (where $i=1,2,3,4$ ). $c_{i}$ is the damping of the drive shafts and half shafts (where $i=1,2,3,4) . J_{i}$ is the equivalent rotary inertia of transmission components (where $i=1, \ldots, 8)$, and their values are listed in Table 3. 
Table 3. The rotary inertia, stiffness and damping of drive shaft.

\begin{tabular}{|c|c|c|c|c|c|c|c|}
\hline \multicolumn{3}{|c|}{ Rotary inertia $\left(\mathrm{kg} \cdot \mathrm{mm}^{2}\right)$} & \multicolumn{2}{c|}{$\begin{array}{c}\text { Stiffness } \\
(\mathrm{N} \cdot \mathrm{m} / \mathrm{rad})\end{array}$} & \multicolumn{2}{c|}{$\begin{array}{c}\text { Damping } \\
(\mathrm{N} \cdot \mathrm{s} \cdot \mathrm{m} / \mathrm{rad})\end{array}$} \\
\hline$J_{1}$ & 1488.122 & $J_{5}$ & 939.644 & $K_{1}$ & 51945.046 & $c_{1}$ & 0.5203 \\
\hline$J_{2}$ & 1798.169 & $J_{6}$ & 19862.712 & $K_{2}$ & 30020.573 & $c_{2}$ & 0.4351 \\
\hline$J_{3}$ & 1970.879 & $J_{7}$ & 11398.368 & $K_{3}$ & 10506.904 & $c_{3}$ & 0.8374 \\
\hline$J_{4}$ & 1969.705 & $J_{8}$ & 122659.200 & $K_{4}$ & 10506.904 & $c_{4}$ & 0.8374 \\
\hline
\end{tabular}

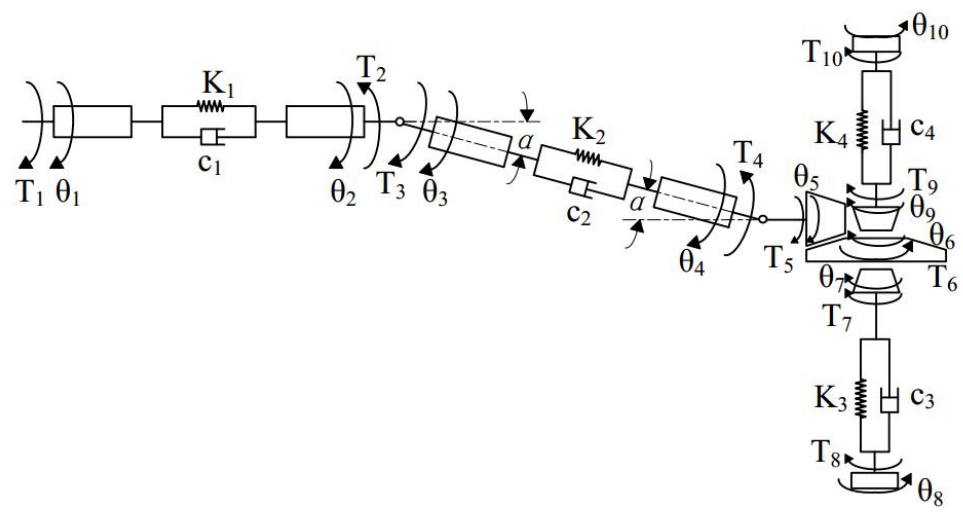

Fig. 3. Torsional vibration model of the shaft-final drive system.

With the reference to the relationship between displacement of shaft and angle between drive shafts [8], the theoretical model for the coupled vibration of the shaft-final drive system can be acquired,

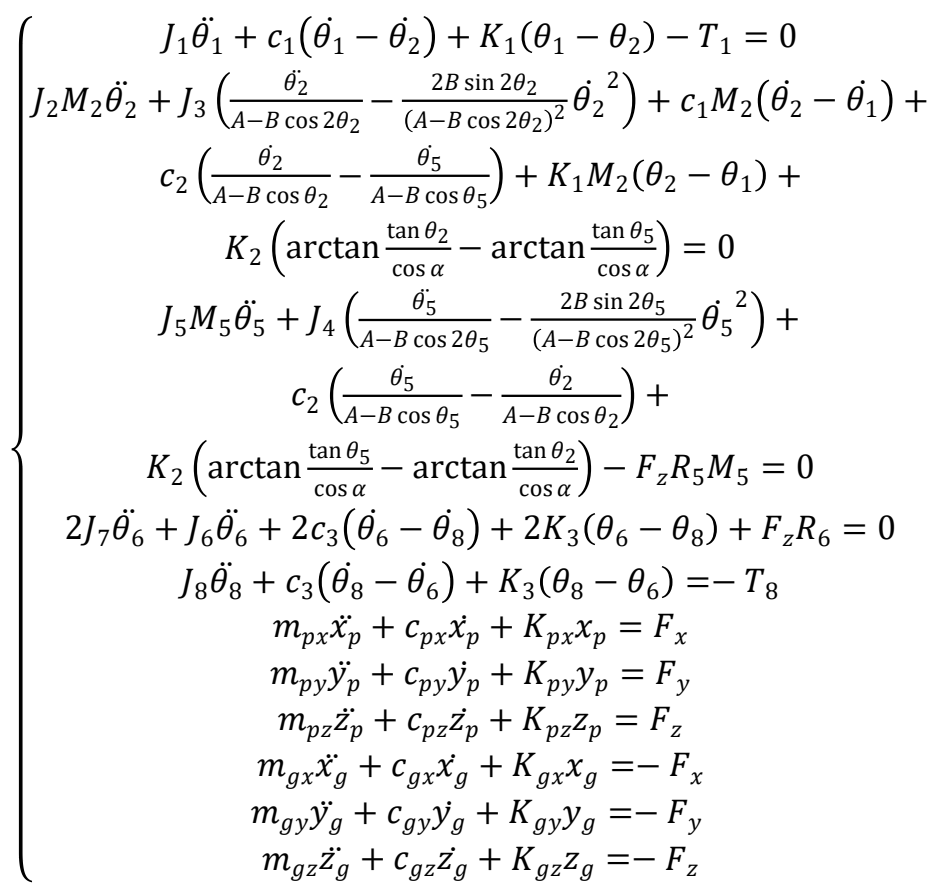


where $m_{i j}$ is the equivalent mass of pinion and gear (where $i=p, g ; j=x, y, z$ ), and $m_{p x}$ $=m_{p y}=m_{p z}=1.04 \mathrm{~kg}, m_{g x}=m_{g x}=m_{g x}=6.16 \mathrm{~kg} . M_{2}=\left(A-B \cos \theta_{2}\right), M_{5}=$ $\left(A-B \cos \theta_{5}\right) . \quad A=\frac{1+(\cos \alpha)^{2}}{2 \cos \alpha}, B=\frac{1-(\cos \alpha)^{2}}{2 \cos \alpha}$.

\section{Results and discussion}

The output torque of the automobile engine is transmitted to main reducer through drive shaft, so the parameters of drive shaft affect the output torque of the engine, which is transmitted to pinion and gear of main reducer. Using the model developed in this paper, the vibration displacement curves of pinion and gear in $x, y$ and $z$ direction at different values of angle between drive shafts, such as $4^{\circ}, 6^{\circ}, 8^{\circ}, 10^{\circ}$ and $12^{\circ}$ are simulated. The effects of the angle between drive shafts on the vibration amplitude are illustrated in Fig. 4(a). It can be seen from Fig. 4(a) that the angle between drive shafts can affect the displacement and vibration amplitude of pinion and gear in $x, y$ and $z$ direction. With the increase of the angle between drive shafts, the vibration amplitudes of pinion and gear in all directions increase. At large angle beyond $6^{\circ}$, the vibration amplitude will increase with the increase of the angle evidently; while at small angle, increasing the angle has little effect on the vibration amplitude. In particular, at small angles such as $4^{\circ}$ and $6^{\circ}$, the vibration responses are similar and the vibration amplitudes are quite small and steady. To acquire the optimum angle, the vibration amplitude of pinion and gear in each direction is simulated with an increment of $0.2^{\circ}$ from $4^{\circ}$ to $6^{\circ}$, and the results are illustrated in Fig. 4(b).

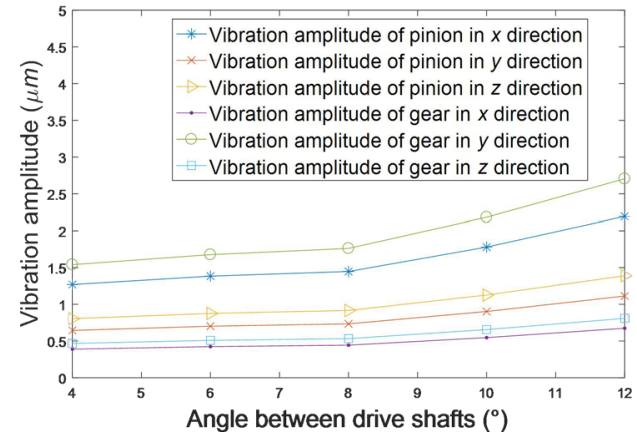

(a)

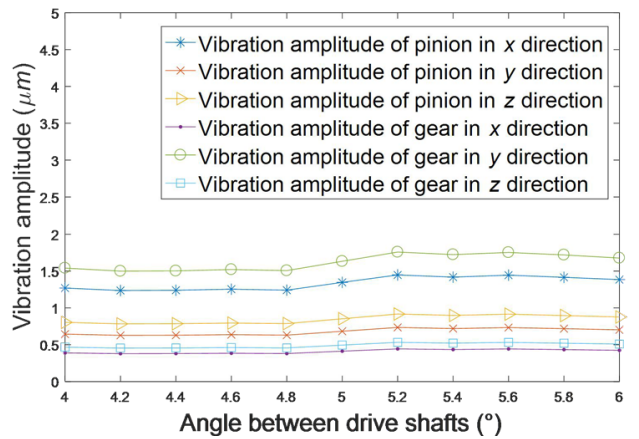

(b)

Fig. 4. Vibration amplitude of pinion and gear in $x, y$ and $z$ direction (a) from $4^{\circ}$ to $12^{\circ}$, (b) from $4^{\circ}$ to $6^{\circ}$.

It can be seen that the vibration amplitudes of pinion and gear in three directions decrease first and then become larger. In particular, the vibration amplitude of pinion and gear in each direction has a minimum value when the angle between drive shafts is $4.2^{\circ}$. In particular, the vibration responses in all directions keep a small value at the range of angle between $4.2^{\circ}$ and $4.8^{\circ}$.

\section{Conclusions}

In this paper, a coupled vibration model of the shaft-final drive system is developed. In the modelling and simulation of this research, the nondimensionalization which is common in previous research is avoided to acquire a clear physical meaning. Using this model, the vibration responses of main reducer at different angles between drive shafts are simulated. In general, the results show that the vibration amplitudes of gears in all three directions 
increase with the angle between drive shafts, especially when it is larger than $6^{\circ}$. In particular, the vibration of the gears at the angle range between $4.2^{\circ}$ and $4.8^{\circ}$ is quite small and stable. Therefore, the model developed in this paper provides an insight for determining the proper angel between drive shafts.

\section{Acknowledgement}

The authors would like to acknowledge the funding from National Natural Science Foundation of China (Grant no. 51505352).

\section{References}

1. R Singh, H Xie and R J Comparin 1989 Analysis of automotive neutral gear rattle Journal of sound and vibration 131 177-196

2. A Kahraman and R Singh 1990 Non-linear dynamics of a spur gear pair Journal of sound and vibration 142 49-75

3. A Kahraman and R Singh 1991 Interactions between time-varying mesh stiffness and clearance non-linearities in a geared system Journal of sound and vibration 146 $135-156$

4. A Kahraman and G W Blankenship 1997 Experiments on nonlinear dynamic behavior of an oscillator with clearance and periodically Journal of Applied Mechanics 64 217-226

5. S Theodossiades and S Natsiavas 2000 Non-linear dynamics of gear-pair systems with periodic stiffness and backlash Journal of sound and vibration 229 287-310

6. J Wang, T C Lim and M Li 2007 Dynamics of a hypoid gear pair considering the effects of time-varying mesh parameters and backlash nonlinearity Journal of sound and vibration 308 302-329

7. X Liu and P A Meehan 2015 Wheel squeal noise: A simplified model to simulate the effect of rolling speed and angle of attack Journal of sound and vibration 338 184-198

8. X Jinli, S Xingyi and P Bo 2015 Numerical analysis and demonstration: transmission shaft influence on meshing vibration in driving and driven gears Shock and Vibration 2015

9. X Liu and P A Meehan 2016 Investigation of squeal noise under positive friction characteristics condition provided by friction modifiers Journal of sound and vibration 371 393-405

10. X Jinli, W Lei and L Wenxin 2016 Influence of bearing stiffness on the nonlinear dynamics of a shaft-final drive system Shock and Vibration 2016 